AUTOR:

Lina Gomes dos SANTOS

ORIENTADOR:

Prof. Dr. Benedito Borges da Silva

\title{
Expressão do oncogene Bcl-2 e do antígeno Ki-67 em carcinoma de mama receptor de estrógeno e progesterona positivo e negativo
}

\section{Resumo de tese}

\author{
Bcl-2 oncogene and Ki-67 antigen expression: a correlation between estrogen \\ receptor-positive and negative breast carcinoma
}

Palavras-chave

Câncer de mama

Oncogene

Receptores hormonais

Ki-67

Dissertação de Mestrado apresentada à Pós-graduação do Centro de Ciências e Saúde da Universidade Federal do Piauí para a obtenção do Título de mestre em Ciências e Saúde, em 4 de agosto de 2006

OBJETIVO: analisar a expressão do oncogene Bcl-2 e do antígeno Ki-67 no carcinoma de mama receptor de estrógeno (RE) e receptor de progesterona (RP) positivos e negativos. MÉTODOS: foi realizado um estudo envolvendo 72 casos de carcinoma ductal infiltrante de mama de mulheres pós-menopáusicas, atendidas nos Hospitais Getúlio Vargas da Universidade Federal do Piauí e São Marcos, no período de 1999 a 2004. Os casos foram divididos em dois grupos: $A$ (RE e RP positivos, $n=37$ ) e B (RE e RP negativos, $n=35$ ). A análise da expressão imunoistoquímica do oncogene Bcl-2 foi feita de um modo semi-quantitativo, utilizando-se a intensidade e a fração das células tumorais coradas e a do Ki-67 foi feita pela contagem de núcleos corados em 500 células tumorais para cada caso. Teste $t$ de Student e teste do $\chi^{2}$ foram usados para análise estatística dos dados e fixou-se o valor de 0,05 ou 5\% para rejeição da hipótese de nulidade. RESULTADOS: A expressão do oncogene Bcl-2 foi significante nos tumores do grupo A (RE e RP positivos) em comparação com os tumores do grupo B (RE e RP negativos), 59,5 e 8,3\%, respectivamente ( $p<0,001$ ). Não houve diferença significante na expressão do antígeno de proliferação celular Ki-67 entre os dois grupos estudados $(p=0,200)$. Dos marcadores estudados, somente o Bcl-2 mostrou uma significante expressão nos tumores de mama receptor de estrógeno e progesterona positivos quando comparados com os tumores negativos.

AUTOR:

Armando Delmanto

ORIENTADOR:

Prof. Dr. Jorge NAHÁs Neto

CO-ORIENTADORA:

\section{Efeito do raloxifeno no epitélio vaginal de mulheres na pós-menopausa}

\author{
Effect of raloxifene on the vaginal epithelium of postmenopausal women
}

Resumo de tese

Palavras-chave

Menopausa Citologia vaginal Raloxifeno
Dissertação apresentada ao Programa de Pós-Graduação em Ginecologia, Obstetrícia e Mastologia, área de concentração em Ginecologia, da Faculdade de Medicina de Botucatu - UNESP, para obtenção do título de Mestre, em 7 de dezembro de 2006

OBJETIVO: analisar o efeito do raloxifeno sobre o epitélio vaginal de mulheres na pós-menopausa. MÉTODOS: estudo prospectivo desenvolvido entre novembro de 2004 e fevereiro de 2006, incluindo 80 mulheres na pós-menopausa. Quarenta pacientes receberam $60 \mathrm{mg} /$ dia de raloxifeno (GR) e 40 mulheres compuseram o grupo não tratado (grupo controle, GCl, pareado por idade e tempo de menopausa. $\bigcirc$ grupo tratado foi composto por pacientes com osteoporose de coluna lombar e/ou colo do fêmur. Foram excluídos aquelas com sinais e/ou sintomas de infecção do trato genital inferior e usuárias de terapia hormonal (TH) até seis meses prévios ao estudo. Os esfregaços vaginais foram coletados em dois momentos: inicial (MO) e após seis meses de seguimento (M1). Para avaliação do epitélio vaginal foi utilizado o valor de maturação, com a contagem de células superficias, intermediárias e parabasais. Os esfregaços foram analisados por único citopatologista, sem conhecimento dos dados das pacientes. Para análise estatística empregouse $o$ teste $t$ de Student, teste Wilcoxon Mann-Witney e o teste $\chi^{2}$. RESULTADOS: na comparação estatística inicial os grupos foram homogêneos. Comparando os momentos inicial e final, não foram observadas diferenças significativas entre os valores medianos de maturação do epitélio vaginal e da porcentagem de células superficiais, intermediárias e parabasais entre os grupos. Não foi constatada correlação linear significativa entre o valor de maturação e a idade, o tempo de menopausa, o uso ou não de TH prévia, tabagismo e o índice de massa corpórea, em ambos os grupos. CONCLUSÃO: o tratamento com raloxifeno por seis meses não alterou o valor de maturação do epitélio vaginal em mulheres na pós-menopausa. 